\title{
ESTUDO SOBRE IMPLANTAÇÃO DE INSTITUIÇÕES PÚBLICAS DE ENSINO SUPERIOR NO BRASIL E NA ITÁLIA. ENTRE O PLANEJAMENTO E O DESENVOLVIMENTO REGIONAL
}

\author{
Maria do Carmo de Albuquerque Braga ${ }^{1}$
}

\begin{abstract}
Resumo: Este artigo objetiva estudar comparativamente a implantação de instituições públicas de ensino superior no Brasil e na Itália, entendendo estas como elo entre planejamento e desenvolvimento regional. Como estudo de casos, adotouse a Universidade Federal Rural de Pernambuco, no Brasil, e a Universidade de Bolonha, na Itália. Sua relevância centra-se em verificar se a proposta de interiorização das universidades, no Brasil, tem contribuído para o desenvolvimento regional, considerando as potencialidades locais. Assim, foram trabalhados autores como Dallari e Curiazi (2012) e Calvo-Sotello (1988). Temporalmente, adotou-se o período entre 2003 e 2010 quando, no Brasil, vivenciou-se a política de expansão do ensino superior, e na Itália, ações definidas desde 1985, aliando expansão ao desenvolvimento regional, baseado no planejamento estratégico focado na integração entre suas unidades e a estrutura urbana. Assim, os dados obtidos indicaram avanços na UFRPE, mas que ainda há muito a ser feito para contribuir com o desenvolvimento regional.
\end{abstract}

Palavras-chave: Espaço Urbano; Desenvolvimento Regional; Planejamento Urbano; Universidades; Políticas Públicas; Educação.

\section{STUDY ON THE IMPLEMENTATION OF PUBLIC INSTITUTIONS OF HIGHER EDUCATION IN BRAZIL AND ITALY. BETWEEN PLANNING AND REGIONAL DEVELOPMENT}

\begin{abstract}
This article aims to conduct a comparative study on the implementation of public universities in Brazil and Italy as links between planning and regional development. The cases of UFRPE in Brazil and UNIBO in Italy were adopted. It is examined whether the move of universities inland has contributed to regional development in order to help Government to use models and territorial typologies compatible with the morphology in which they are inserted. Authors Dallari and Curiazi (2012) and Calvo-Sotello (1988) were used as references. The period 20032010 in Brazil was framed because of the expansion policy used, and in Italy, the years after 1985, combining expansion and regional development, based on planning and integration of facilities in the urban fabric. In conclusion, it was found through the

\footnotetext{
Docente da Universidade Federal Rural de Pernambuco (UFPE) - Unidade Acadêmica de

Estudos Geográficos, Rio Claro, 17(1): 195-216, jan./jun. $2019 \quad$ (ISSN 1678-698X) http://www.periodicos.rc.biblioteca.unesp.br/index.php/estgeo
} Garanhunsmariabraga77@gmail.com
\end{abstract}


data obtained progress in UFRPE but also a need to do much more in order to contribute to regional development.

Keywords: Urban Space; Regional Development; Urban Planning; Universities; Public Policy; Education.

\section{INTRODUÇÃO}

Este artigo compreende um estudo comparativo sobre implantação de instituições de ensino superior públicas no Brasil e na Itália, entendendo essas instituições enquanto elo entre o planejamento e o desenvolvimento regional. Sua relevância se dá em função da necessidade de se verificar se a proposta de interiorização das universidades, no Brasil, tem contribuído para o desenvolvimento regional, considerando as potencialidades locais, visto que a proposta tem como fundamento minimizar as diferenças sociais, econômicas e culturais entre as regiões do país, e dar a oportunidade para as pessoas se qualificarem e poderem se estabelecer em suas regiões de origem. Assim, a intenção é de auxiliar o planejamento governamental a encontrar caminhos para fortalecer o desenvolvimento regional, por meio da implantação de modelos e tipologias de estruturas físicas de instituições de ensino superior (IES) que sejam compatíveis com o contexto em que se inserem. Para viabilizar o trabalho, adotou-se como estudo de casos a Universidade Federal Rural de Pernambuco (UFRPE), no Brasil e a Universidade de Bolonha (UNIBO), na Itália.

Dessa forma, o artigo foi estruturado em cinco partes: na primeira, aborda-se a criação e a inserção de universidades em diferentes contextos urbanos; na segunda, são estudadas as diferentes formas de planejamento e concepção de estruturas físicas de universidades existentes; na terceira, foi analisada a situação da UFRPE e suas extensões; na quarta, expõe-se o caso da UNIBO e seu processo de expansão, e, por fim, faz-se uma reflexão sobre o que foi abordado no trabalho, identificando avanços para o caso da UFRPE, mas que ainda há o que se ajustar.

\section{A CRIAÇÃO E INSERÇÃO DE UNIVERSIDADES EM CONTEXTOS URBANOS COMO AMPLIAÇÃO DO ENSINO}

A história das universidades, no Brasil e no mundo já foi abordada por diversos autores como Santos e Almeida Filho (2008) e Prado Coelho (1999). A presente análise inicia-se como estabelecimento do ensino superior na Europa, passando por diversas experiências, com diferentes modelos e tipologias espaciais. Nesse contexto, contou-se com a inovação alemã, a proposta humboldtiana, somando-se com o recente Processo de Bolonha, em que os países signatários da União Europeia (EU) se comprometeram em compatibilizar seus sistemas, para atender as demandas das pessoas, no continente. Outros modelos também se expressaram como o Norte Americano, proposto por Abraham Flexner. Este e o Alemão também contribuíram para a formação do sistema brasileiro.

Assim, percebe-se que a adoção de um modelo pode influenciar no desenvolvimento local ou regional. Nisso, a história mostra que aliar o desenvolvimento à educação foi estratégia notadamente comprovada como caminho ideal para o sucesso de uma sociedade. No dizer de Dallari e Curiazi (2012, p.85)

Estudos Geográficos, Rio Claro, 17(1): 195-216, jan./jun. 2019 (ISSN 1678-698X) http://www.periodicos.rc.biblioteca.unesp.br/index.php/estgeo 
"El desarrollo de la civilización comunal favorece el nacimiento de uma nueva sociedade $y$, em consecuencia, de uma nueva y diferente demanda cultural", resultando em seu desenvolvimento.

No Brasil, a implantação de IES ocorreu de forma similar a da Europa, o que se explica pelo país ter sido uma colônia portuguesa e, por isso, o privilégio de usufruir dessas instituições era exclusividade da elite (SANTOS e ALEMIDA FILHO, 2008). A situação começa a mudar penas em 1808, com a chegada da família real portuguesa ao Brasil. Segundo dados sobre universidades no Brasil (IPEA, 2010, n.p.).

Até o final do século XIX, era privilégio da elite dominante: não havia mais que 10 mil estudantes em 24 escolas. Foi a partir da Constituição republicana de 1891 que a iniciativa privada entrou em cena e multiplicou a oferta de vagas, a partir de São Paulo - em três décadas, o número de instituições de ensino superior pulou para 133.

O sistema prevalente nessas instituições era o europeu, com suas tradições. Contudo, durante o regime militar, ocorreu a primeira grande reforma, surgindo o caráter de Universidade, cujo modelo traduzia-se em um misto entre o NorteAmericano e o Alemão, que nas palavras de Santos e Almeida Filho (2008, p. 137), resultou "em uma espécie de salada, ou talvez um pequeno monstro, um Frankenstein acadêmico, tanto em termos de modelo de formação quanto de estrutura institucional". O autor ainda destaca que, na década de 1960, a ideia era disseminar o conhecimento, fazendo com que a população jovem e menos favorecida financeiramente tivesse a oportunidade de acesso a essas instituições (SANTOS e ALMEIDA FILHO, 2008).

Aos poucos esse objetivo se degradou, especialmente durante a fase de democratização do país, quando as universidades passaram por um período de inércia, associado a problemas de "subfinanciamento, caos administrativo, crise de autoridade, desvalorização social, manifestos em longas, frequentes e frustrantes greves de estudantes, docentes e servidores" (SANTOS e ALMEIDA FILHO, 2008, p.138).

Araújo (2014) cita vários programas entre as políticas públicas que foram implantadas com o objetivo de adequar as IES públicas no país, entre eles o PROUNI - Programa Universidade para Todos; o REUNI - Programa de Apoio a Planos de Reestruturação e Expansão das Universidades Federais. Além desses, Araújo (2014) analisa também os PPA - Planos Plurianuais, com destaque para o PPA para 2008 a 2011, que previu apoio à residência multifuncional e à Assistência ao estudante do ensino de graduação.

$\mathrm{Na}$ avaliação das ações de interiorização do ensino superior, ressalta-se um número grande de universidades implantadas nas diferentes regiões, mas que a maioria delas ainda se concentra na região Sudeste, onde há abundância de infraestrutura viária, de transporte e de outras facilidades para a população. Situação inversa encontra-se no Nordeste, e mais ainda na região Norte. Nestas, ressalta-se a dificuldade de mobilidade dos estudantes e, consequentemente, sua permanência no ensino superior, o que denota a importância de um estudo prévio de localização para implantação de IES em regiões interioranas e, além disso, melhor atenção ao conteúdo da proposta física a ser implantada.

Estudos Geográficos, Rio Claro, 17(1): 195-216, jan./jun. 2019 (ISSN 1678-698X) http://www.periodicos.rc.biblioteca.unesp.br/index.php/estgeo 


\section{PLANEJAMENTO E CONCEPÇÃO ESPACIAL DE UNIVERSIDADES NO BRASIL E NA ITÁLIA}

O planejamento para implantação de uma IES não é antigo, antiga é sua origem. Na Europa, o ensino era basicamente ofício desenvolvido nos mosteiros, locus do conhecimento, além de "(...) uma primitiva rede escolar em abadias beneditinas (...) A laicização do conhecimento começa a partir do advento dos centros urbanos medievais, embora o locus do conhecimento ainda fosse religioso. As catedrais eram os centros de estudos (...)" (RODRIGUES, 2001, apud NEVES et al., 2012, p.03). Assim, as instituições de ensino da época passaram por várias transformações, tanto no que concernem os modelos de sistema como das tipologias espaciais.

Nesse contexto de mudanças surgiu a universidade moderna na Europa, tendo como referências os modelos alemão e francês, sendo este último sob o regime napoleônico, cuja abrangência incluía parte da Itália. Esses modelos serviram de base para as transformações das demais universidades do ocidente e cada um expressou-se no espaço urbano diferentemente: cidade universitária ou campus. Nesse sentido, Pinto e Buffa (2006, p. 5737), ao debaterem o tema, concordam com Neves et al. (2012) ao declararem que campus e cidade universitária são conceitos definem não apenas o mesmo espaço, mas cumprem os mesmos objetivos, embora ressaltem que campus seria o mais adequado para a situação brasileira, pois refere-se a um território fechado, com administração independente, abrigando espaços de ensino e pesquisa e alguns poucos serviços como lanchonetes, copiadoras e restaurante.

O modelo italiano formou-se a partir de Bolonha, onde se encontra a reconhecida instituição mais antiga do ocidente e que apesar disso, também recebeu influência do modelo territorial francês, cidade universitária. Sua forma de inserção no espaço urbano, ao longo dos anos, não diferiu muito das demais instituições, apenas seu estabelecimento, passando de simples corporações à universidade.

As modificações ocorreram em função do desenvolvimento e expansão das cidades. Os edifícios passaram a se constituir em prédios de dois ou três pavimentos, normalmente formados por ambientes que se misturavam entre moradia e trabalho para os professores, estando inseridos de forma geminada, em ruas estreitas. Comenta Verger (1990) que por não serem edifícios apropriados para a atividade de ensino, alguns dos eventos como debates solenes, exames e cerimônias oficiais normalmente se desenvolviam em conventos ou igrejas. Este foi o caso de Bolonha, que também oferecia "alimentação, segurança e liberdade acadêmica" como disseram os autores. Assim, o crescimento das cidades europeias foi ocorrendo, fazendo com que serviços, moradia e comércio que antes compunham o núcleo central da cidade, estivessem disponíveis nos novos centros em surgimento. Dessa forma, as hospedarias passaram a abrigar salas de ensino, pois os professores entenderam que seria interessante oferecer seus serviços no local onde os alunos já se encontravam.

As transformações se aprofundaram ainda mais quando as universidades começaram a clamar por espaços, passando das salas de ensino ou universitas às salas góticas, somando-se à necessidade prática de bibliotecas que já se consolidavam enquanto componente fundamental para as instituições (VERGER, 1990). Em termos urbanísticos, esses novos prédios foram implantados nos limites

Estudos Geográficos, Rio Claro, 17(1): 195-216, jan./jun. 2019 (ISSN 1678-698X) http://www.periodicos.rc.biblioteca.unesp.br/index.php/estgeo 
das cidades, sendo os novos cursos localizados próximos aos existentes, resultando em um conglomerado de edifícios urbanos, formando posteriormente as universidades. Pinto e Buffa (2006, p. 5732) ressaltam que "a cidade se mesclava aos edifícios escolares e, posteriormente, esse conjunto acabou por tornar-se espaço pertencente a uma universidade e, apesar de apartado da cidade, aparece na malha urbana como continuidade dela".

Em Bolonha, as modificações se deram diferente, já que em função das exigências de Napoleão Bonaparte, em 1802, o Plano Geral de Educação aprovado em 1798, foi adaptado para abrigar a Faculdade de Direito, Belas Artes, Filosofia e Medicina, resultando no nascimento da Universidade Nacional do antigo Studium, o que ocasionou o rompimento do antigo vínculo existente entre a instituição e a cidade, além de comportamentos e privilégios próprios da Idade Média.

As mudanças ocorridas provocaram uma reorganização do espaço urbano, particularmente no quadrante nordeste, para onde a Universidade foi transferida, ocupando uma série de conventos abandonados, de acordo com as novas regras definidas pelo poder Napoleônico. A organização do espaço da cidade privilegiou, portanto, a ocupação de vazios urbanos ou mesmo prédios religiosos abandonados, como nos relata Dallari e Curiazi (2012).

Entre as mudanças que ocorreram em Bolonha, em função da inserção da universidade, destaca-se a de 1985, quando a instituição se preparava para as comemorações de seus 900 anos de existência. Na ocasião foi elaborado um plano de inserção e expansão da IES, bem como interação com o desenvolvimento local e regional.

Observando a diversidade de formas de inserção bem como de modelos de IES no espaço urbano, Calvo-Sotelo (2011) realizou estudos, oferecendo critérios para identificação de cada um. Em seus estudos, o autor (2011) faz referência a modelos espaciais importantes surgidos ao longo do tempo. No período Medieval, identificou que a universidade se estabeleceu e começou a tomar corpo a partir do êxodo do saber de dentro dos claustros das catedrais e monastérios, indo ao encontro da sociedade, quando se evidenciou a necessidade de edifícios próprios e funcionais, distante dos centros urbanos. Surgia, assim, o que o autor (2011, p.152) denominou de cidade do estudo, deixando a configuração policêntrica no tecido urbano, para conjuntos de edifícios compactos, dotados de ambientes como salas de aula, biblioteca, entre outros, em plantas de forma quadrada ou retangular, organizadas em torno de um pátio, normalmente com uma torre. Bolonha já se apresentava como referência por apresentar uma forma diferente, aliando "espaço e tempo, reunidos fisicamente em uma mesma forma arquitetônica".

No período Moderno, o autor chama a atenção para o modelo britânico, o college, que se multiplicando rapidamente, formou a segunda cidade do saber, herdando a forma arquitetônica de plantas quadradas ou retangulares, sendo um "(...) legado da arquitetura monástica, enquanto o claustro foi um espaço marcado pela ordem formal no qual se desenvolvia a vida estudantil" (CALVO-SOTELO, 2011, p. 153). Assim, a partir da organização claramente geométrica, foi adaptandose à malha urbana e à reprodução de múltiplas fachadas fechadas, facilitando a identificação entre a universidade e a cidade.

Ao contrário, o modelo francês baseado na subordinação ao Estado, deu início à reforma do imponente edifício da Universidade de Sorbone, de tipologia concentrada e monoestrutural para estruturas dispersas, policêntricas, fragmentadas em departamentos autônomos, no interior da malha urbana. O modelo alemão, segundo 0 autor, baseado na verdade pela verdade, apresentava-se em

Estudos Geográficos, Rio Claro, 17(1): 195-216, jan./jun. $2019 \quad$ (ISSN 1678-698X) http://www.periodicos.rc.biblioteca.unesp.br/index.php/estgeo 
O primeiro bloco apresenta três modelos de distribuição: Territorial; Local; e, Associado. Por territorial, entende que seja uma universidade que tenha uma estrutura policêntrica e equidistribuída espacialmente, em grande escala de abrangência, sem possuir sede destacada. Por local, aquela que tem sede própria centralizada e polarizada em relação ao grande centro urbano, mesmo tendo representação em outros municípios, podendo ainda possuir pequenos centros de educação à distância distribuídos no território. Por associado denomina o modelo que se liga a populações de escala mediana, cuja característica compreende-se pela existência de outro elemento urbano de referência.

Para análise da estrutura territorial, o autor aponta dois tipos: Monorecinto ou monocampus; e Multirecinto ou multicampus. Os dois primeiros referem-se ao modelo que apresenta apenas um espaço diferenciado, enquanto os dois últimos à estrutura de universidade com mais de um espaço diferenciado.

Quanto aos modelos de localização, estes se diferenciam de modelos de distribuição, pois trata do vínculo entre a instituição e a cidade. Dessa forma, apresenta-se em quatro situações: (a) Desvinculado; (b) Polarizado; (c) Superperiférico; e, (d) Urbano. Este último ainda se subdivide em outras quatro subcategorias: Periférico; Como Tecido Urbano; Isolado no Interior Urbano; Difuso no Interior Urbano.

O modelo desvinculado refere-se ao que a universidade tem uma localização longe o suficiente da cidade para se compreender que as ligações entre ambas são mínimas. Derivado do anterior, por polarizado se entende ser aquele que apresenta também uma separação física considerável do tecido urbano da cidade, mas não inclui o componente extramuros intencional. Superferiférico é aquele em que as edificações também se apresentam notoriamente separadas do tecido urbano da cidade, mas estão diretamente ligadas a uma cidade-satélite, que é significativamente menor entidade dimensional. Por urbano se denomina o modelo em que os edifícios educacionais estão diretamente relacionados com o tecido urbano da cidade e que, por esse motivo, subdivide-se nas quatro subcategorias anteriormente citadas. Quanto à relação Universidade-Cidade, o autor aponta duas categorias: (a) Integração; e (b) Segregação. Com esta análise o autor ressalta o tipo de relação entre a Universidade e a Cidade.

Ainda em suas análises, o autor identifica os submodelos componentes do segundo bloco como sendo três: (a) Universidade e Entorno; (b) Ordenamento, Forma e Estrutura; e, (c) Estrutura Compositiva Interna. Cada um desses apresenta submodelos que se referem às condições internas, excetuando-se o primeiro, ou seja, Universidade e Entorno, cuja relação do interno com o externo interessa para o objetivo deste trabalho, e que pode ser do tipo introvertido ou extrovertido. $O$ introvertido refere-se àquele que apresenta relações abertas com seu entorno, natural ou artificial, enquanto o extrovertido, aquele que revela relação em segundo plano com seu entorno.

Com desse entendimento, torna-se viável analisar modelos de implantação de IES ou realizar análise comparativa entre modelos implantados, no Brasil e no exterior, de forma a se obter resultados que apontem para seu sucesso ou não.

Estudos Geográficos, Rio Claro, 17(1): 195-216, jan./jun. $2019 \quad$ (ISSN 1678-698X) http://www.periodicos.rc.biblioteca.unesp.br/index.php/estgeo 


\section{A UNIVERSIDADE FEDERAL RURAL DE PERNAMBUCO E SUAS EXTENSÕES}

O Relatório de Atividades 2013 (UFRPE, 2014) esclarece que a origem da Instituição data de 1912, mas só em 1955 passou a integrar o sistema federal de ensino superior. Desde então, tem desenvolvido atividades na área da Agricultura e mais recentemente nas ciências sociais, exatas e humanas. $\mathrm{O}$ campus sede situa-se em Recife, capital do estado e tem ampliado suas atividades em diferentes regiões do estado por meio de extensões universitárias, com o objetivo de aumentar a oferta de matrículas e assim poder atender a demanda nessas regiões, lançando mão da localização de seus "órgãos suplementares" (UFRPE, 2014) espalhados no estado, além de cumprir com o que ficou estabelecido pelo planejamento estratégico adotado desde 2013. Apesar disso, persiste a dificuldade na contabilização de dados de um ano para o outro, o que pode ser constatado nos Relatórios de Atividades até então produzidos. Para este trabalho foram selecionados três relatórios como pode ser visto no Quadro 2.

\section{Quadro 2 - Números e inovação da Universidade Federal Rural de Pernambuco nos anos 2013/2014/2015}

\begin{tabular}{|c|c|c|c|}
\hline ANOS DA PESQUISA & 2013 & 2014 & 2015 \\
\hline Alunos matriculados & 10.995 & 12.841 & \\
\hline Média de Produtos de pesquisa* & 3.213 & 3.189 & 2.898 \\
\hline Departamentos ${ }^{* *}$ & 22 & 21 & 20 \\
\hline Faculdades ${ }^{\star * *}$ & 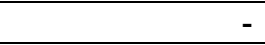 & - & 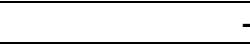 \\
\hline Centro de pesquisa e treinamento ${ }^{\star \star * *}$ & 8 & 8 & 8 \\
\hline Campus ${ }^{* \star \star \star *}$ & 3 & 4 & 4 \\
\hline Programas de Graduação & 49 & 56 & 56 \\
\hline $\begin{array}{lll}\text { Programas } & \text { de } & \text { Graduação } \\
\text { Internacional }^{\star \star \star \star \star *}\end{array}$ & - & - & 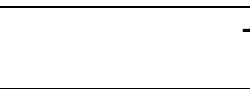 \\
\hline Programas pós-graduação & $\begin{array}{l}17 \mathrm{PhD} \\
- \text { Esp. } \\
31 \text { Mest }\end{array}$ & $\begin{array}{l}15 \text { PhD } \\
- \text { Esp. } \\
30 \text { Mest }\end{array}$ & $\begin{array}{l}- \text { PhD } \\
\text { - Esp. } \\
\text { - Mest }\end{array}$ \\
\hline $\begin{array}{l}\text { Alunos Estrangeiros em Programas de } \\
\text { Intercâmbio }\end{array}$ & 21 & 9 & 6 \\
\hline $\begin{array}{lll}\text { Programas de } & \text { Colaboração Acadêmica } \\
\text { Internacional } & \text { e transferência de } \\
\text { conhecimento } & & \\
\end{array}$ & 55 & - & \\
\hline Acordos Internacionais para Estágio & - & - & - \\
\hline $\begin{array}{l}\text { Acordos entre UFRPE, empresas e } \\
\text { instituições públicas, privadas para } \\
\text { inserção no Mercado de trabalho }{ }^{* * * * * *}\end{array}$ & - & - & - \\
\hline $\begin{array}{l}\text { Funcionários (professores, técnicos e } \\
\text { administrativos) }\end{array}$ & 2.059 & 2.252 & \\
\hline Orçamento da Universidade ${ }^{* \star * * \star * \star}$ & $267.551 .661,17$ & $318.217352,81$ & $349.662 .669,55$ \\
\hline
\end{tabular}

* - Dados produzidos pela autora do trabalho, a partir de informações fornecidas pela PRPPG.

É o somatório dos números de: Patentes; Capítulos de livros; Livros; Trabalhos completos em Anais de eventos; Artigos publicados em periódicos.

** - Embora exista o Departamento de Registro e Controle Acadêmico e figura na estrutura organizacional da UFRPE, não integra a contagem total dos Departamentos Acadêmicos que compõem a Instituição.

*** - Não se aplica a UFRPE, em função de sua estrutura.

Estudos Geográficos, Rio Claro, 17(1): 195-216, jan./jun. 2019 (ISSN 1678-698X) http://www.periodicos.rc.biblioteca.unesp.br/index.php/estgeo 
**** - Os centros de pesquisa da Universidade são denominados ora por estações avançadas (5), ora por campus que, somados aos centros de pesquisa (3), realizam trabalhos de pesquisa, treinamento e ensino.

***** - Campus só há um: o que abriga a Sede, pois os demais são Unidades Acadêmicas, ou melhor, extensões universitárias, portanto, sem autonomia.

$* * * * \star *$ - Não informado.

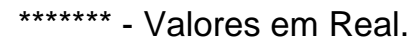

Fonte: Universidade Federal Rural de Pernambuco, 2013/2014/2015.

O Relatório de 2015 encontrava-se em desenvolvimento em quase todo o ano de 2016, o que dificultou a elaboração da pesquisa, apresentando vários problemas como dados desencontrados, incompletos, inexistentes, barreira burocrática na obtenção dos mesmos e dificuldade na disponibilização. Os dados apresentados no quadro 2 mostra aumento no número de alunos matriculados, no número de funcionários, além de no número de programas de graduação. Por outro lado, mostra um decréscimo no número de programas de pós-graduação e no número de alunos estrangeiros em Programas de intercâmbio e transferência de conhecimento, denotando pouca ação de internacionalização.

No que se refere a tipologias e modelos definidos por Calvo-Sotelo (2011) verifica-se que a estrutura física da sede, no espaço urbano do Recife, é bem particular. O prédio principal, que abriga a Reitoria, foi projetado em 1935, para um reformatório de menores. Os demais prédios destinados aos departamentos foram construídos ao longo dos anos, de forma dispersa, em bairro periférico a cidade (Figura 1). Essa situação, em termos positivos, implicou no usufruto de uma temperatura mais amena e numa tranquilidade que emana do verde de seu entorno. Em termos negativos, aponta-se a distância entre os blocos onde se encontram os diversos serviços prestados pela Universidade, inclusive as salas de aula.

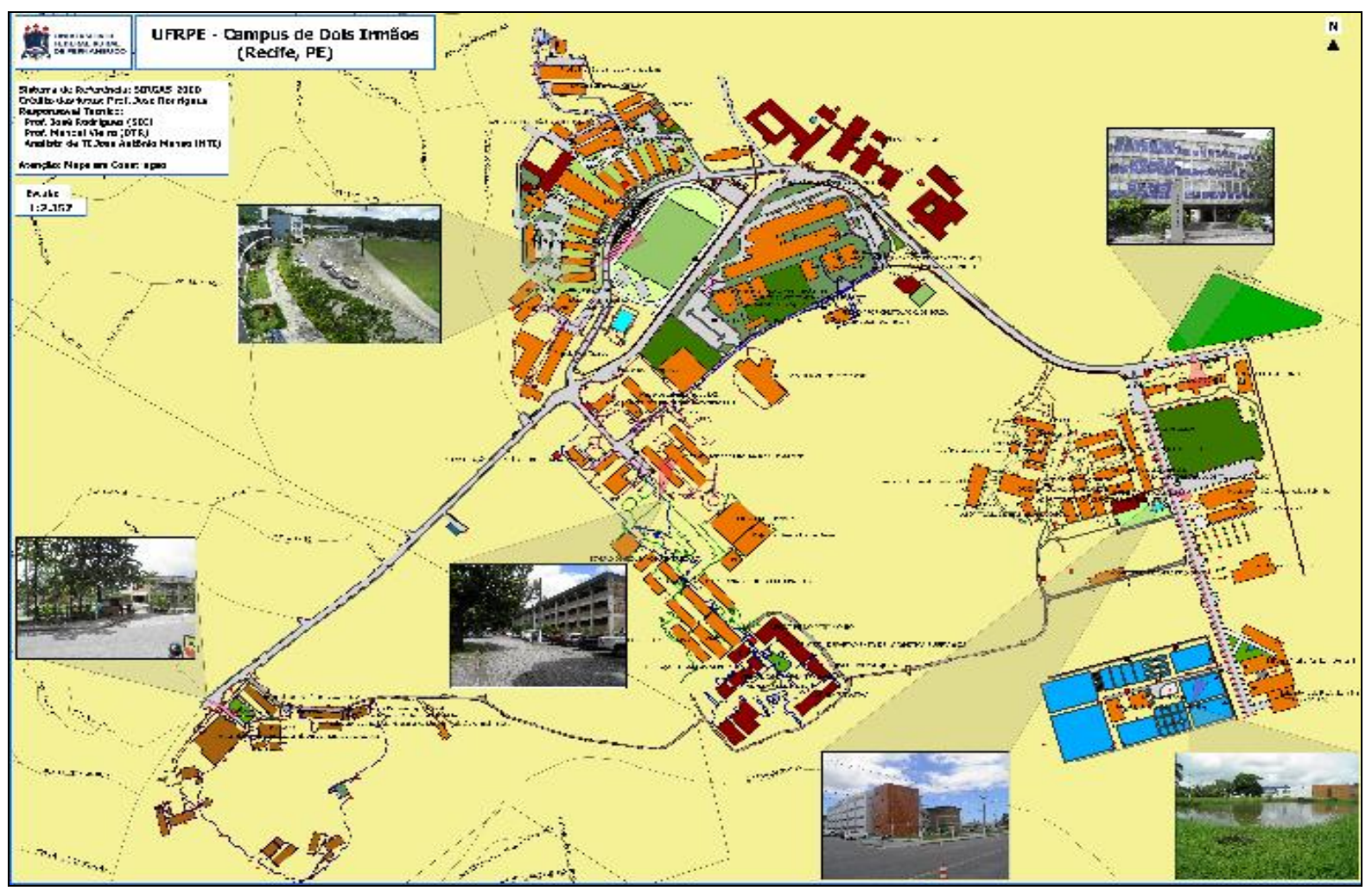

Figura 1 - Localização da estrutura física da UFRPE-Sede, em Recife.

Fonte: UFRPE, 2016

Estudos Geográficos, Rio Claro, 17(1): 195-216, jan./jun. 2019 (ISSN 1678-698X) http://www.periodicos.rc.biblioteca.unesp.br/index.php/estgeo 
A Unidade Acadêmica de Garanhuns (UAG), a primeira extensão do país, iniciou suas atividades em 2005, com os cursos de Agronomia, Medicina Veterinária, Zootecnia e Licenciatura Normal Superior. Em 2009, foram incluídos três novos cursos, através do Programa REUNI: Engenharia de Alimentos, Ciência da Computação e Letras. A área para implantação da unidade foi cedida pelo Governo do Estado e situa-se às margens da BR-424, na periferia de Garanhuns, região do Agreste Meridional do Estado. Com 13 anos de existência, a Unidade ainda não dispõe de toda estrutura física planejada para seu funcionamento adequado, o restaurante universitário é um deles (Figuras 2).

A Unidade Acadêmica de Serra Talhada (UAST) foi inaugurada em 2006, em Serra Talhada, região do Sertão pernambucano. De início, oferecia seis cursos: Agronomia, Bacharelado em Ciências Biológicas, Bacharelado em Ciências Econômicas, Engenharia de Pesca, Bacharelado em Sistemas de Informação e Licenciatura Plena em Química. Em 2010, foram incluídos três novos: Licenciatura em Letras, Administração e Zootecnia. A Unidade insere-se fora do contexto urbano do município (Figura 3), ocupando o Centro de Treinamento e Pesquisa em Pequena Irrigação, um dos campi avançados da UFRPE.

A Unidade Acadêmica do Cabo de Santo Agostinho (UACSA), em Cabo de Santo Agostinho, mesmo situando-se a 10min do Centro do município, às margens da BR-101, insere-se na periferia, assim como as demais unidades. (Figura 4).

O objetivo foi atender a demanda oriunda do Complexo Industrial Portuário de Suape e entorno, oferecendo cinco cursos de engenharia: Civil, Materiais, Elétrica, Eletrônica e Mecânica, com isso diversificando as áreas de atuação da IES.

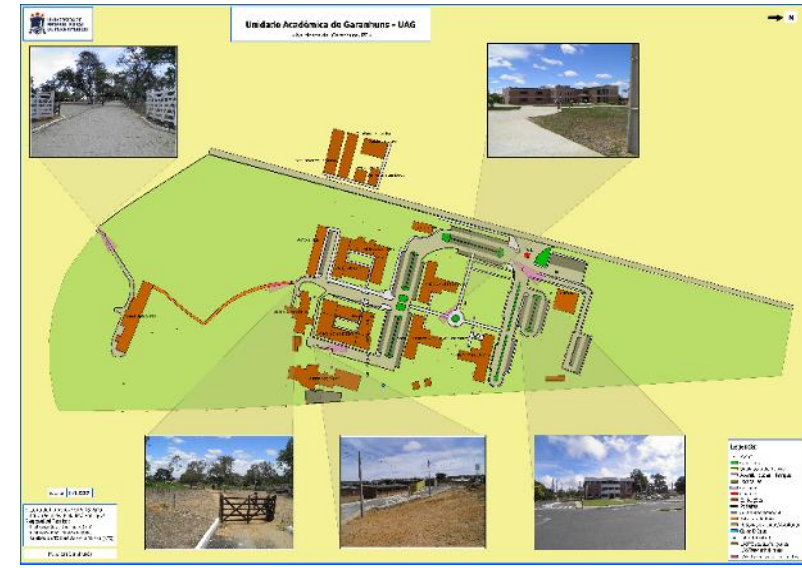

Figura 2 - Localização da estrutura física da UAG, Garanhuns.

Fonte: UFRPE, 2016.

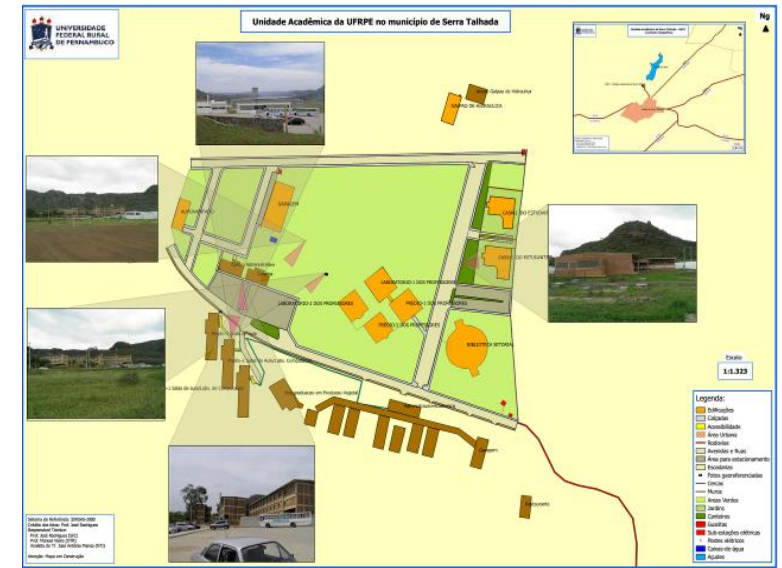

Figura 3 - Localização da estrutura física da UAST, em Serra Talhada.

Fonte: UFRPE, 2016 


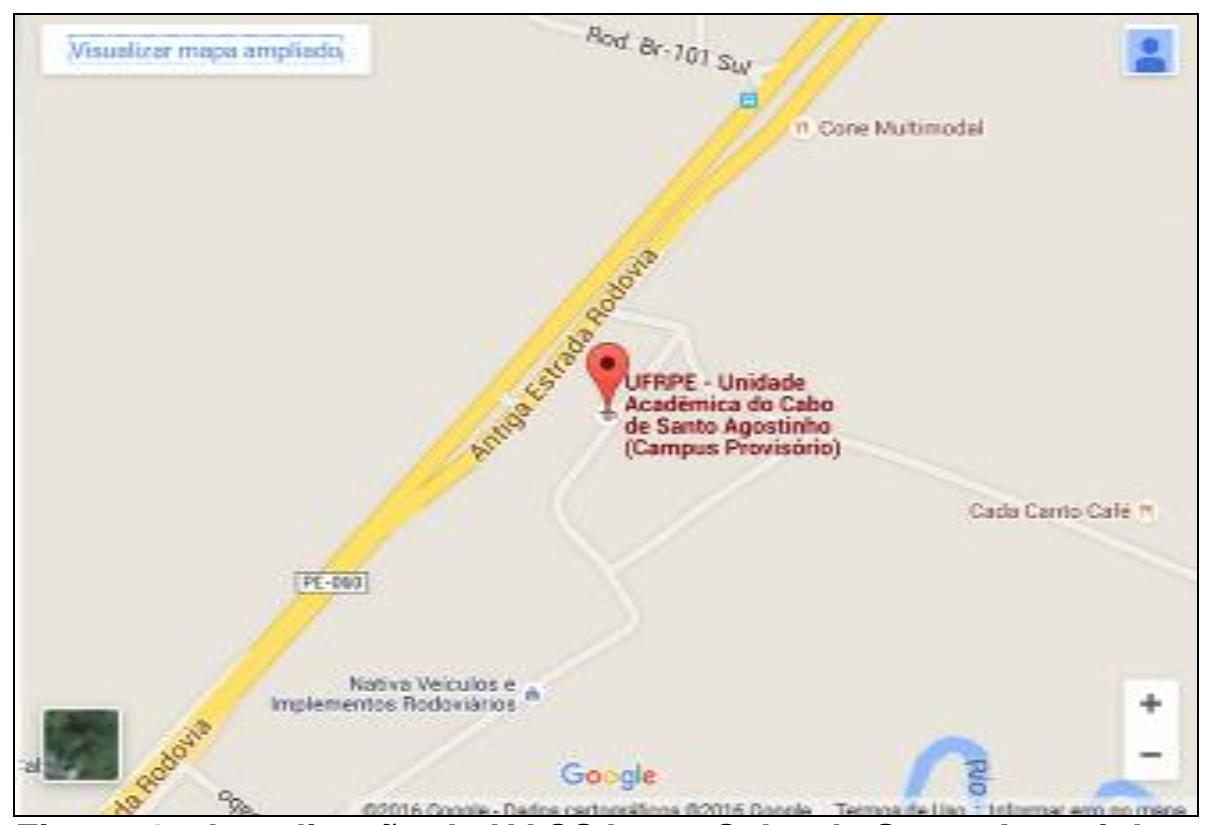

Figura 4 - Localização da UACSA, em Cabo de Santo Agostinho.

Fonte: UFRPE, 2016.

Trata-se de um projeto audacioso, segundo esclarece o último relatório analisado, pois traz consigo alguns diferenciais: inovação e empreendimento, e apoio financeiro para os alunos.

\section{A UNIVERSIDADE DE BOLONHA E SEUS CAMPI}

Bolonha é capital da Província de Bolonha, na Itália. Faz parte da região da Emília Romagna, localizando-se entre os rios Reno e Savena, além de se situar no cruzamento de diferentes meios de comunicação terrestres e marítimos e se constituir em um dos maiores centros educacionais, tendo em seu território a mais antiga universidade do mundo: a Alma Mater Studiorum - Università di Bologna.

Entre os aspectos que contribuíram para a consolidação da Instituição na região, observa-se sua aderência por estudantes do mundo, especialmente do continente europeu. A estratégia de inserção da Universidade e sua relação com o espaço urbano tem sido um diferencial para seu reconhecimento enquanto a Alma Mater das Universidades. Sua expansão tem se dado há algum tempo, mas foi, sobretudo, a partir de 1985, quando se aliou ao desenvolvimento urbano e regional, como expõem Dallari e Curiazi (2012). De início, privilegiou trabalhar com os campi do entorno, expandindo-se, posteriormente para áreas cujo potencial coincidia com os interesses da Universidade.

As autoras afirmam que a proposta faz parte do Programa Decenal da Universidade que, nessa fase, a meta foi montar uma estratégia em rede, consolidando o papel da Instituição no espaço urbano. A estratégia baseou-se na ideia de cidade-região e Universidade-sistema. Os nós seriam formados pela rede de lugares, cidades onde são estimuladas práticas de aprendizagem, formação e investigação, segundo os potenciais locais.

Assim, a UNIBO estruturou seu plano de metas de forma a: (1) reforçar sua presença na Europa, fomentando a internacionalização e transferência de tecnologia; (2) cuidar da qualidade de ensino e a qualidade da investigação,

Estudos Geográficos, Rio Claro, 17(1): 195-216, jan./jun. 2019 (ISSN 1678-698X) http://www.periodicos.rc.biblioteca.unesp.br/index.php/estgeo 
promovendo internacionalização; (3) investir na capacitação da equipe, corpo docente e técnicos administrativos. Além desses pontos foi acrescida a proposta de estrutura multicampus.

A Universidade conta com a sede, em Bolonha, quatro campi (Forlì, Rimini, Cesena e Ravenna), além da recente unidade internacional na cidade de Buenos Aires, Argentina.

Em termos territoriais, a Universidade sempre teve uma relação espacial estreita com a cidade, porém a partir de 1985, foi adotado um plano de expansão aliado ao desenvolvimento urbano, com intensificação dessa relação.

Segundo Dallari e Curiazi (2012), o Plano previa que a cidade metropolitana se dividiria em áreas especializadas e integradas, em função das características históricas da região da Emilia Romagna, que constituía um polo urbano altamente descentralizado, formado por centros urbanos que se transformariam em matrizes de vocação radiocêntrica. Os nós compreenderiam projeções descentralizadas na região a partir dos bairros históricos de Bolonha, regiões Nordeste e Noroeste, projetando-se também sobre os novos bairros da Universidade, ou seja, o Centro Histórico, Lazzaretto e Navile, além dos centros universitários metropolitanos como Ozzano de Emília e Cadriano.

Com base nessa estratégia, a intenção era de tratar o desenvolvimento urbano e regional, definindo papéis a serem desempenhados pelas instituições acadêmicas da região, segundo o potencial existente em cada uma delas. Para tanto, planejou recuperar e reutilizar edifícios urbanos desocupados como meio de expansão, começando pela cidade de Bolonha e, posteriormente, em Forlì, Cesena, Ravenna e Rimini bem como nas cidades de pequeno porte como Ozzano de Emília e Bertinoro, e nas zonas rurais.

O plano de ação conta com quatro níveis. O primeiro é o mais central e é também a origem, pois é formado pela estrutura principal da Universidade, não apenas a atual, mas e principalmente a futura, compreendendo o centro histórico antigo e o novo. Este nível envolve grandes avenidas de circulação, espaços de memória, para onde se destinam preferencialmente 0 Departamento de Humanidades da Universidade.

O segundo nível concentra-se a sudoeste, para onde estão destinadas as áreas de tecnologia, aproveitando o potencial local das grandes indústrias, possibilitando futuros projetos de parceria com departamentos científicos e tecnológicos e com laboratórios que devem conectar-se com produção, pesquisa e indústria de serviços na cidade.

O terceiro nível, no âmbito metropolitano, como explica Dallari e Curiazi (2012), compreende o espaço além das comunas, abrange os polos externos de Ozzano e se entrelaça com os polos do Sistema Universitário Regional de Ferrara e Módena.

Por fim, o quarto nível, o regional, compreende o território de novas fronteiras administrativas, descentralizadas da Universidade, contemplando perspectivas futuras. Assim, a incorporação dos campi universitários foi ocorrendo em sequência, buscando trabalhar dentro das novas exigências impostas pela legislação atual.

O campus de Cesena foi o primeiro a ser incorporado. O segundo foi o de Rimini, que em 1972 iniciou os primeiros cursos. O terceiro foi o de Ravenna, sendo a primeira unidade descentralizada da UNIBO, em 1986. O campus de Forlì foi o último a ser incorporado, sendo também o primeiro resultado do processo de ramificação da Universidade baseada no sistema Multicampus, tendo início em

Estudos Geográficos, Rio Claro, 17(1): 195-216, jan./jun. 2019 (ISSN 1678-698X) http://www.periodicos.rc.biblioteca.unesp.br/index.php/estgeo 
2001. Assim, após reformas promovidas nas unidades descentralizadas e na sede o sucesso das ações tem sido frequente. (Quadro 3).

\section{Quadro 3 - Números e inovação da Universidade de Bolonha nos anos 2013/2014/2015}

\begin{tabular}{|c|c|c|c|}
\hline$\underbrace{\text { ANO DA }}_{\text {ITENS PESQUISADOS }}$ & 2013 & 2014 & 2015 \\
\hline Alunos matriculados & 87.000 & 86.014 & 84.215 \\
\hline Média de Produtos de pesquisa & 12.000 & 11.000 & 11.000 \\
\hline Departamentos & 33 & 33 & 33 \\
\hline Faculdades & 11 & 11 & 11 \\
\hline Centro de pesquisa e treinamento & & & 9 \\
\hline Campus & 5 & 5 & 5 \\
\hline Programas de Graduação & 212 & 209 & 207 \\
\hline Programas de Graduação Internacional & 40 & 43 & 52 \\
\hline Programas pós-graduação & $\begin{array}{l}53 \mathrm{PhD} \\
50 \text { Esp. } \\
61 \text { Mest }\end{array}$ & $\begin{array}{l}51 \mathrm{PhD} \\
47 \mathrm{Esp} \text {. } \\
64 \text { Mest }\end{array}$ & $\begin{array}{l}48 \mathrm{PhD} \\
41 \text { Esp. } \\
71 \text { Mest }\end{array}$ \\
\hline $\begin{array}{l}\begin{array}{l}\text { Alunos Estrangeiros em } \\
\text { Intercâmbio em } 2012\end{array} \\
\end{array}$ & 2.365 & 2.280 & 2.288 \\
\hline $\begin{array}{lcc}\text { Programas de } & \text { Colaboração Acadêmica } \\
\text { Internacional } & \text { e transferência de de } \\
\text { conhecimento aprovados entre 2011-2012 }\end{array}$ & 63 & Mais que 100 & Mais que 136 \\
\hline Acordos Internacionais para Estágio & 170 & 170 & 273 \\
\hline $\begin{array}{l}\text { Acordos entre Alma Mater, empresas e } \\
\text { instituições públicas, privadas para inserção } \\
\text { no Mercado de trabalho }\end{array}$ & 9.826 & - & \\
\hline $\begin{array}{l}\text { Funcionários (professores, técnicos e } \\
\text { administrativos) }\end{array}$ & 5.982 & 5.942 & 5.921 \\
\hline Orçamento da Universidade & $\begin{array}{r}628,3 \text { milhões } \\
\text { de Euros }\end{array}$ & $\begin{array}{r}631,5 \text { milhões } \\
\text { de Euros }\end{array}$ & $\begin{array}{r}603,7 \text { milhões } \\
\text { de Euros }\end{array}$ \\
\hline
\end{tabular}

Fonte: Universidade de Bolonha, 2015.

Os dados do quadro indicam pequena variação para menor em número de programas de graduação e pós-graduação, especialmente quanto à $\mathrm{PhD} e$ Especialização, diferente do Mestrado, com um leve aumento. Nota-se ainda sensível aumento nos programas de Colaboração Acadêmica Internacional bem como em Acordos Internacionais para Estágio, denotando estratégia de internacionalização da Instituição.

Em Bolonha, o campus da Universidade (Figura 5) está inserido no contexto do antigo centro histórico. Não se distinguem as edificações que servem a universidade daquelas que servem a outros usos. O que se verifica é uma forte dinâmica urbana promovida pelos diversos usos existentes na cidade: inerentes e complementares. Toda a estrutura da UNIBO distribui-se no centro histórico de tal forma que não se percebe pontos de inércia, pois a dinâmica urbana, através de fluxo de pessoas (cidadão comum, estudantes, professores, turistas, empresários, etc.), de transporte, de mercadorias, de encontros, etc., se faz presente a qualquer hora do dia ou da noite.

Estudos Geográficos, Rio Claro, 17(1): 195-216, jan./jun. 2019 (ISSN 1678-698X) http://www.periodicos.rc.biblioteca.unesp.br/index.php/estgeo 


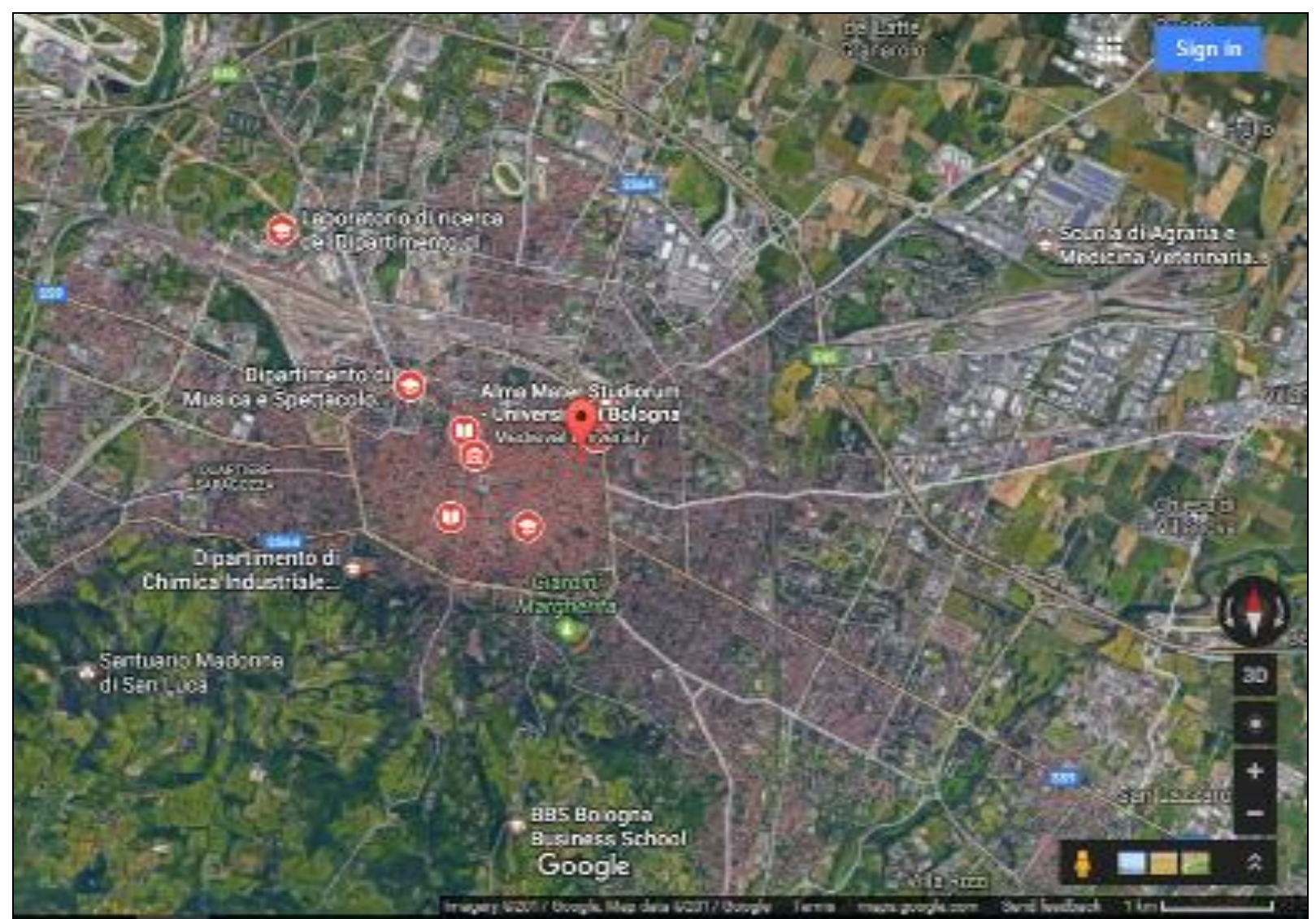

Figura 5 - Inserção da estrutura física da Universidade de Bolonha, em Bolonha.

Fonte: Google Maps, 2016.

Essa estratégia também foi adotada nas extensões da Universidade em Forlì, Cesena, Ravenna e Rimini, que passaram por transformações, inicialmente se constituindo em um posto avançado, Centro de Ensino e Pesquisa, integrando-se posteriormente à Instituição segundo o plano de estrutura multicampus.

Entre 2013 e 2014, o poder municipal ofereceu à Universidade a antiga área Staveco, com $92.000 \mathrm{~m}^{2}$, para a construção de um novo campus dos quais $52.000 \mathrm{~m}^{2}$ se destinaria a parques e espaços abertos. Essa proposta encontra-se em desenvolvimento e segundo o site da UNIBO, apresentava objetivos como: (1) Renovar o "pacto" com a cidade; (2) Aumentar o tamanho da Universidade no cenário internacional; (3) Apoiar concretamente o direito à Educação; (4) Promover a sustentabilidade ambiental; (5) Cumprir o Plano de Construção da Universidade; (6) Racionalizar as estruturas físicas no contexto da cidade. O fundo financeiro para sua implantação apoia-se na Lei Italiana no. 338, relativa ao Direito à Educação, que não implica em problema para o orçamento da Instituição, como esclarece o site da Universidade.

A unidade da cidade de Forlì constitui o primeiro dos exemplos de descentralização da Universidade de Bolonha (Figura 6) em toda região da Emília Romagna, sendo criado em 2001. Já em 1989, alguns cursos existentes no antigo Centro de Ensino e Pesquisa foram ampliados, como o curso de Economia e o de Engenharia.

$\mathrm{Na}$ oportunidade, foram potencializados programas para inaugurar o posto avançado da Universidade de Bolonha. Os cursos de Ciências Políticas, de Licenciatura em Ciências Políticas com foco Internacional e uma Escola Superior em

Estudos Geográficos, Rio Claro, 17(1): 195-216, jan./jun. 2019 (ISSN 1678-698X) http://www.periodicos.rc.biblioteca.unesp.br/index.php/estgeo 
Línguas Modernas para Intérpretes e Tradutores passaram a ser oferecidos. Com a transformação de posto avançado em campus, Forlì assistiu a ampliação de ofertas de cursos, contando também com Engenharia.

Em 2003, o Centro de Ensino de Forlì ganhou um Centro de Línguas para as áreas Científicas e de Ensino. Atualmente, os cursos ofertados em Forli, além dos já existentes, destacam-se especialização Aeroespacial, especialização em Engenharia e Arquitetura e grau em Sociologia e Criminologia executado pela Escola de Ciência Política. Em adição, também foram implantados programas de pós-graduação, incluindo mestrado. Planos futuros para o campus incluem a recuperação da área do antigo Hospital Morgan com o objetivo de fortalecer seu papel no contexto multicampus da Universidade.

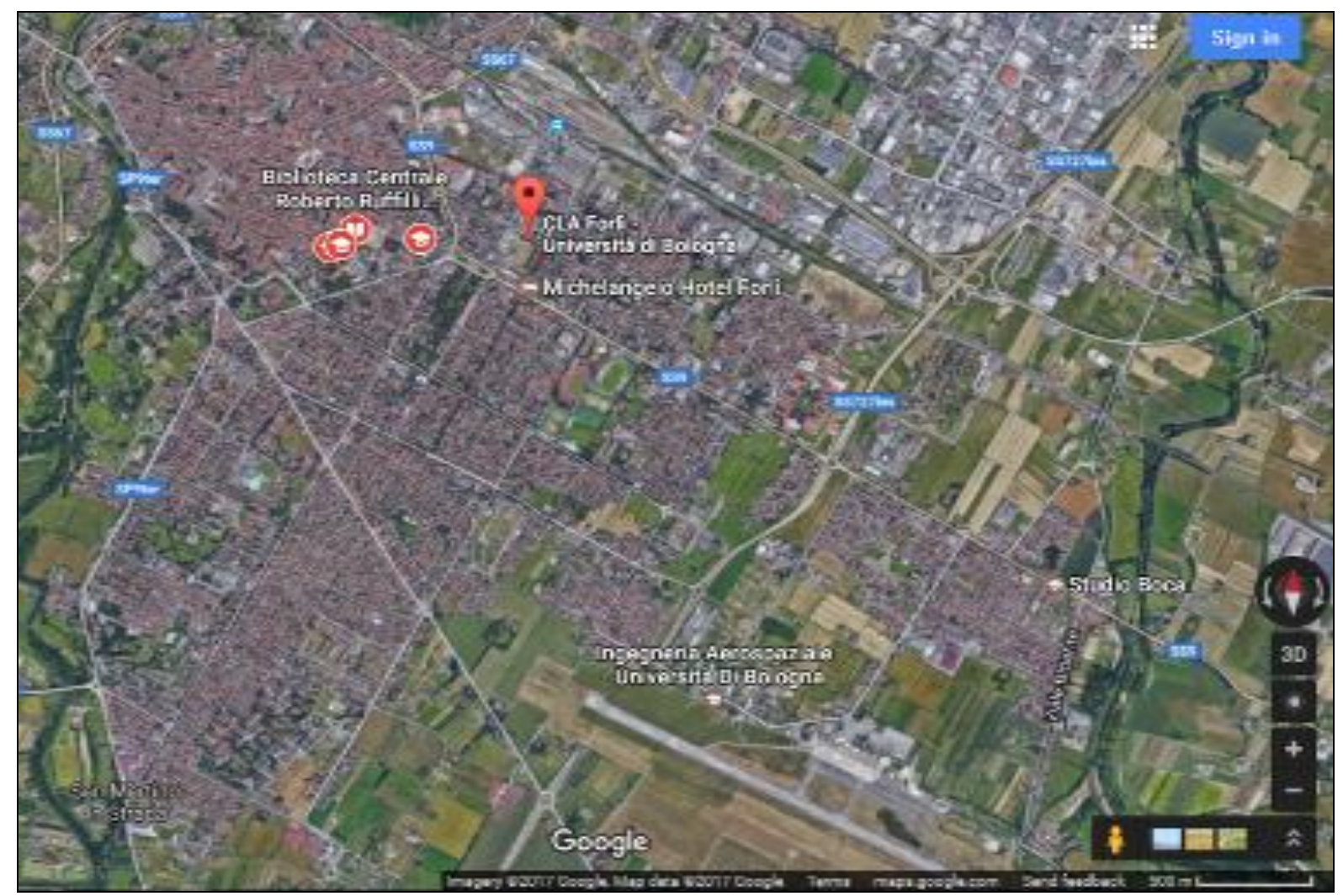

Figura 6 - Inserção da Universidade de Bolonha, em Forlì.

Fonte: Google maps, 2016.

Em Cesena, o nascer de um centro científico e de ensino ocorreu no ano de 1504 (UNIVERSITÀ DI BOLOGNA, 2015), mas logo se deu seu fechamento, no ano de 1800. Pouca resistência foi oferecida diante do ocorrido e menor ainda a capacidade de se refazer o centro que já dava sinais de consolidação. Apenas em 1989, a UNIBO encampou Cesena como uma Unidade descentralizada (Figura 7), reativando o antigo papel de centro de ensino, com a implantação de um Programa de Licenciatura em Ciência da Informação.

Estudos Geográficos, Rio Claro, 17(1): 195-216, jan./jun. 2019 (ISSN 1678-698X) http://www.periodicos.rc.biblioteca.unesp.br/index.php/estgeo 


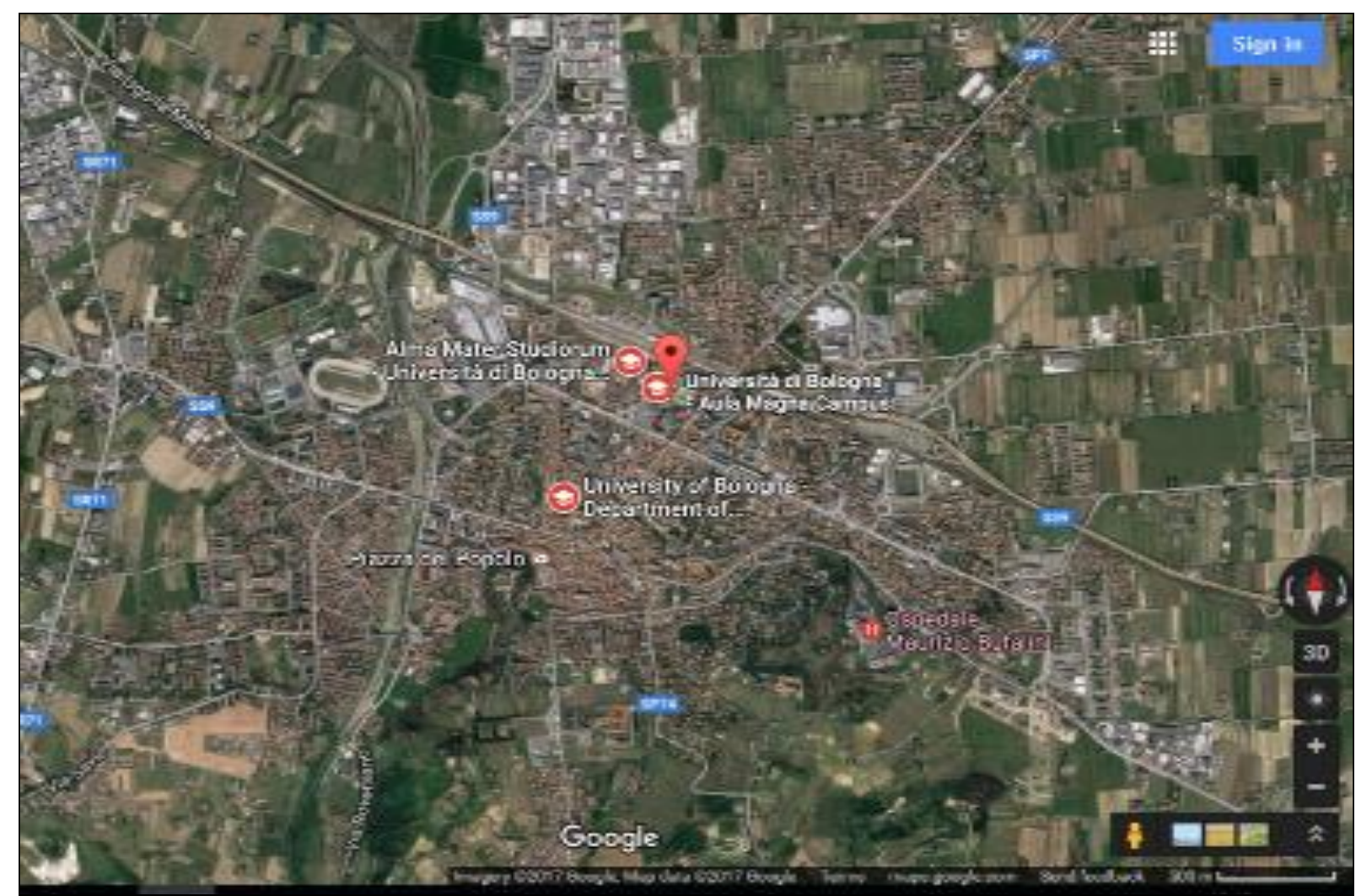

Figura 7 - Inserção da Universidade de Bolonha, em Cesena.

Fonte: Google Maps, 2016.

O sucesso do Programa contou com o apoio de empresas locais, no fornecimento de laboratórios, bibliotecas e salas de aula, se tornando um marco na expansão territorial da Universidade de Bolonha em direção a uma região que não dispunha de centros de ensino.

Atualmente, o projeto de futuro do campus é a construção de uma Escola de Engenharia e Arquitetura, como parte do planejamento de renovação urbana, com a recuperação da estrutura física da antiga fábrica de açúcar, dando lugar a alojamentos, escritórios e residências para estudantes e professores. Além disso, outros imóveis antigos e sem usos serão recuperados e formarão o mais avançado complexo politécnico da região.

Em Ravenna, o Centro de Ensino e Científico iniciou suas atividades no final dos anos 1980, coincidindo com o nono centenário da Universidade de Bolonha e a Declaração de Bolonha. Ravenna contou com o primeiro curso de secretariado de forma descentralizada, como uma extensão da Universidade de Bolonha (Figura 8). Já em 1988, surgiu o primeiro curso superior para arquivista e, em 1989, para Ciências Ambientais, se tornando posteriormente um novo campus. A ampliação do Centro em Ravenna baseou-se em pesquisas sobre as vocações locais e com isso, foram indicados: Programas ligados à História, à conservação do patrimônio cultural; uma série de escavações em todos os cantos do mundo, o que demanda diferentes tipos de laboratório e um programa de graduação em Ciência Ambiental voltada à proteção do habitat.

Estudos Geográficos, Rio Claro, 17(1): 195-216, jan./jun. 2019 (ISSN 1678-698X) http://www.periodicos.rc.biblioteca.unesp.br/index.php/estgeo 


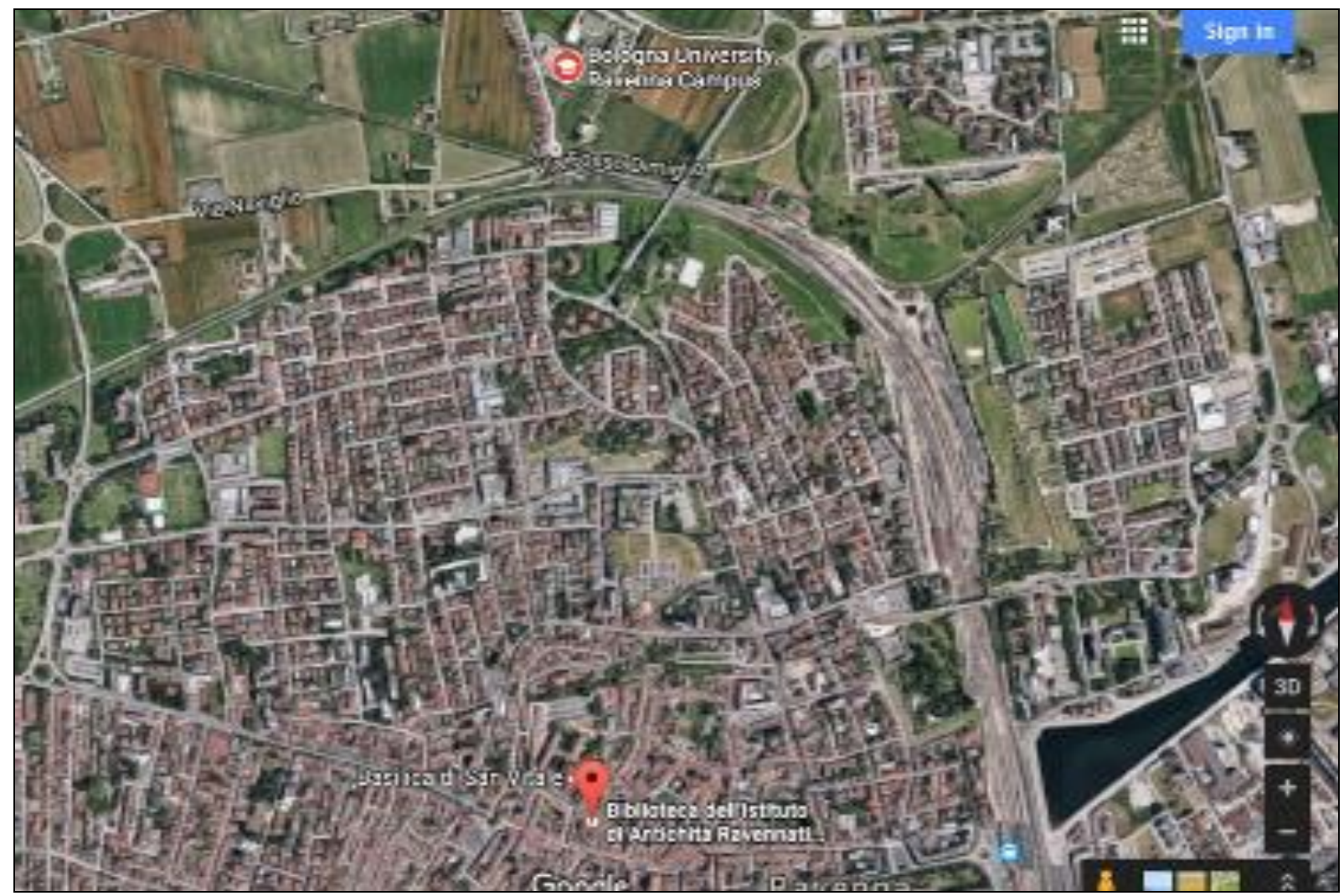

Figura 8 - Inserção da Universidade de Bolonha, em Ravenna.

Fonte: Google Maps, 2016.

Recentemente, o Centro ampliou sua oferta de cursos, com base nas vocações pesquisadas: Dois programas de graduação em Direito; programas na área de saúde como Fonoaudiologia, Enfermagem e Medicina; programas em construção como Engenharia civil e graus relacionados à conservação e restauração do patrimônio cultural, cuja abrangência consolida uma maior capilaridade da Universidade em toda região. Além desses cursos, foram também implantados programa em Química e Tecnologia relacionado ao meio ambiente e materiais; programa em Engenharia e de sistemas urbanos; programa em Biologia Marinha, bem como em Análise e Gestão do Ambiente.

Em Rimini, já funcionavam cursos superiores desde 1972. A ampliação da oferta de cursos nos anos 1980 se deu nas áreas de Economia e Estatística, denotando um potencial considerado na área acadêmica. Logo surgiram cursos como Química Industrial, Moda, Farmácia, Ciência Motor, Medicina e Ciência da Educação, demonstrando a mesma lógica de distribuição da estrutura física da UNIBO, em que a integração, a adequação, a coerência e o equilíbrio refletem o grau de aderência da Universidade ao local (Figura 9).

O resultado dessa estratégia tem se verificado com o aumento do número de jovens que têm vínculo com a UNIBO advindos de outras áreas da Itália, da Europa e do mundo, indicando o sucesso do trabalho de planejamento desenvolvido pela da Universidade. Em 1998, a internacionalização de fato da Universidade de Bolonha foi consolidada com a inauguração do campus em Buenos Aires, Argentina. Com esta nova unidade, a Universidade tem ampliado suas ações para além do continente europeu.

Estudos Geográficos, Rio Claro, 17(1): 195-216, jan./jun. 2019 (ISSN 1678-698X) http://www.periodicos.rc.biblioteca.unesp.br/index.php/estgeo 


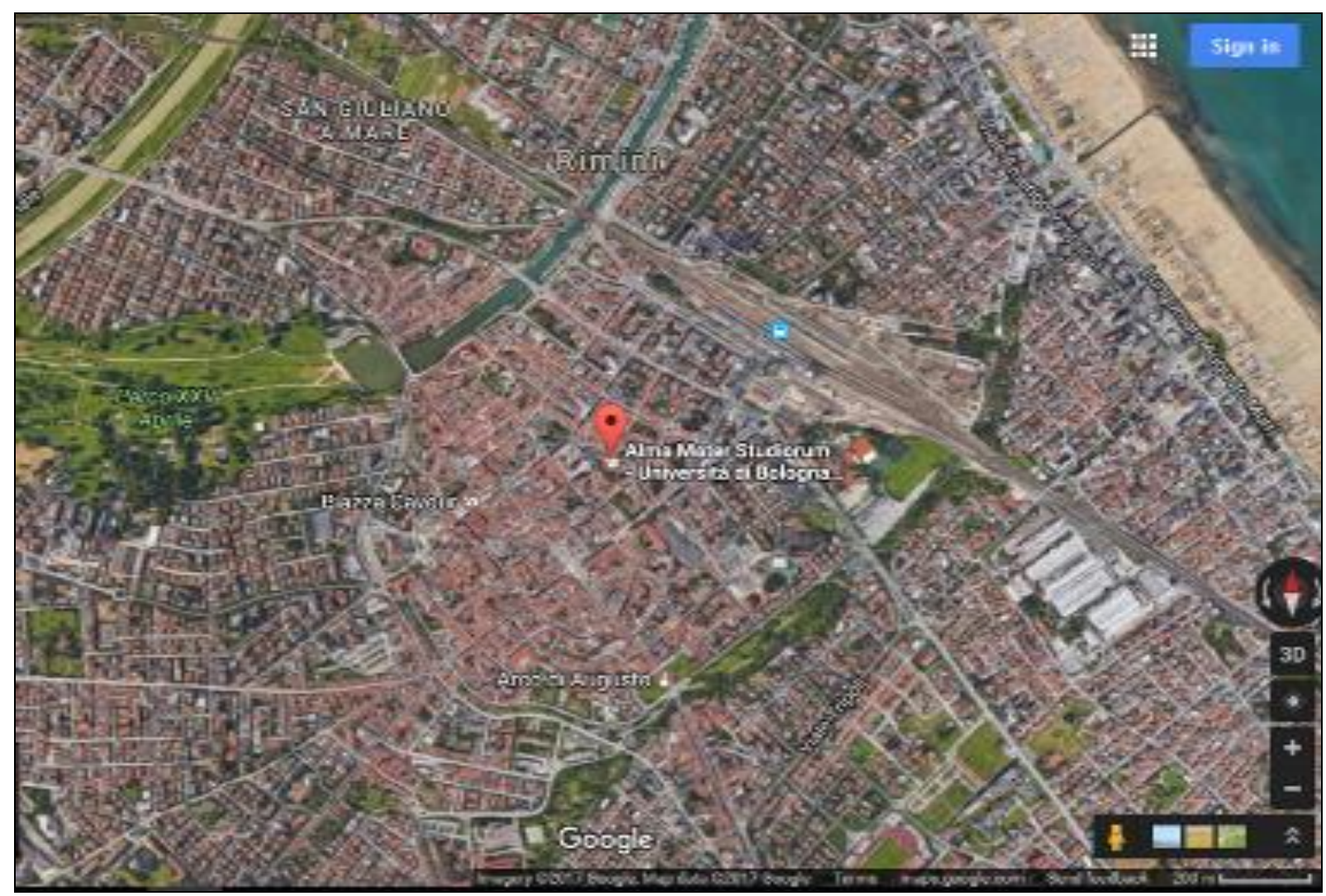

Figura 9 - Inserção da Universidade de Bolonha, em Rimini.

Fonte: Google Maps, 2016,

A criação desse campus teve como objetivo maior a preparação e capacitação de profissionais na área de gerenciamento de empresas, especialmente aquelas que lidam com negócios internacionais, particularmente dirigidos entre a União Europeia e a América Latina. A intenção é fazer com que os profissionais formados possam se inserir no contexto atual de globalização e inovação, entre países de trato político democrático.

\section{CONSIDERAÇÕES FINAIS}

A partir da necessidade de verificar se a proposta de interiorização das universidades tem contribuído para o desenvolvimento regional, considerando as potencialidades locais e regionais, esta pesquisa tomou como referência o caso da Universidade de Bolonha, na Itália para verificar: (1) em que medida esta lança mão das potencialidades regionais, contribuindo efetivamente para o desenvolvimento regional; e, (2) em que medida, na Itália, ocorre de fato algo novo cuja experiência possa ser trazida para o Brasil.

Com tal propósito, o primeiro aspecto a ser tratado é o modelo territorial adotado. Este, embora seja oriundo de decisão de gestão, influencia diretamente na forma como a Instituição desenvolve suas atividades, interage internamente com seus departamentos, e, externamente com as demais Instituições, mas principalmente como contribui para o desenvolvimento da região, dialogando com 0 contexto urbano em que se insere.

Como visto, a inserção territorial das universidades brasileiras se deu de diferentes formas ao longo do tempo, mas que nunca chegou a incorporar um

Estudos Geográficos, Rio Claro, 17(1): 195-216, jan./jun. 2019 (ISSN 1678-698X) http://www.periodicos.rc.biblioteca.unesp.br/index.php/estgeo 
modelo específico. A não adoção de um modelo não contribui positivamente para uma gestão que tenha como base um plano estratégico de ação, contemplando ações integradas, mas ações sequenciais semelhantes, no dizer de Pinto e Buffa (2006) em "um círculo vicioso", que se inicia com a desapropriação ou doação de área, normalmente distante do centro urbano e continua com a necessidade de um plano e um projeto arquitetônico, cujas obras normalmente são paralisadas após inauguração, por falta de verbas, ao fim de uma gestão.

Observa-se que o planejamento estratégico adotado pela universidade para a inserção de suas expansões conduziu a UFRPE a caminhos que não viabilizam efetivamente o cumprimento dos objetivos em contribuir para o desenvolvimento regional. A UAG é um bom exemplo, iniciando com o acordo entre os três níveis de governo, mas que não houve maior contribuição das partes para seu sucesso, o que tem contribuído sobremaneira para sua falta de protagonismo no desenvolvimento da região. Mesmo ainda não dispondo de toda sua estrutura física, em 2017, solicitou sua emancipação ao Ministério de Educação e Cultura (MEC), sendo aprovada através da Lei Federal 13.651/2018, tornando-se a Universidade Federal do Agreste de Pernambuco, que incluiu a recém-criada Unidade Acadêmica de Belo Jardim (UABJ) sob seu comando. Esta Unidade situa-se também na região do Agreste do estado e ainda não tem sua estrutura física implantada.

O exemplo da UNIBO é importante, pois a estratégia adotada, tanto para a sede como para seus campi, ocorre por espraiamento no espaço urbano, em função das potencialidades locais, aliadas aos seus objetivos. A integração, a adequação, a coerência e o equilíbrio adotados como estratégia de inserção da Universidade no contexto urbano e a parceria entre os governos tem resultado na oferta da infraestrutura necessária ao sucesso.

Considerando os estudos de Calvo-Sotelo (2011) sobre identificação de diferentes modelos e tipologias que podem auxiliar o planejamento a potencializar 0 papel de IES públicas no contexto em que se inserem ou ainda na implantação de novas unidades, é possível observar as diferenças entre a UFRPE e a UNIBO (Quadro 4).

Estudos Geográficos, Rio Claro, 17(1): 195-216, jan./jun. $2019 \quad$ (ISSN 1678-698X) http://www.periodicos.rc.biblioteca.unesp.br/index.php/estgeo 
Quadro 4 - Classificação de modelo e tipologia da Universidade de Bolonha e da
Universidade Federal Rural de Pernambuco, a partir dos estudos de Calvo-Sotelo (2011)

\begin{tabular}{|c|c|c|c|c|c|}
\hline \multirow{2}{*}{\multicolumn{2}{|c|}{$X$}} & \multicolumn{2}{|c|}{ Distribuição } & \multirow{2}{*}{ Localização } & \multirow{2}{*}{$\begin{array}{c}\text { Relação } \\
\text { Universidade } \\
\text { Cidade }\end{array}$} \\
\hline & & Espacial & Estrutura & & \\
\hline \multicolumn{2}{|c|}{ UNIBO - Bolonha } & Territorial & Multicampus & $\begin{array}{l}\text { Urbano - Difuso } \\
\text { no interior urbano }\end{array}$ & Integração \\
\hline \multirow{4}{*}{$\begin{array}{l}\text { Extensões } \\
\text { Interioranas }\end{array}$} & Rimini & Territorial & Multicampus & $\begin{array}{l}\text { Urbano - Difuso } \\
\text { no interior urbano }\end{array}$ & Integração \\
\hline & Forlì & Territorial & Multicampus & $\begin{array}{l}\text { Urbano - Difuso } \\
\text { no interior urbano }\end{array}$ & Integração \\
\hline & Ravenna & Territorial & Multicampus & $\begin{array}{l}\text { Urbano - Difuso } \\
\text { no interior urbano }\end{array}$ & Integração \\
\hline & Cesena & Territorial & Multicampus & $\begin{array}{l}\text { Urbano - Difuso } \\
\text { no interior urbano }\end{array}$ & Integração \\
\hline \multicolumn{2}{|c|}{ UFRPE - Recife } & Local & Multicampus & Desvinculado & Segregação \\
\hline \multirow{3}{*}{$\begin{array}{l}\text { Extensões } \\
\text { Interioranas }\end{array}$} & Garanhuns & Local & Multicampus & Desvinculado & Segregação \\
\hline & $\begin{array}{l}\text { Serra } \\
\text { Talhada }\end{array}$ & Local & Multicampus & Desvinculado & Segregação \\
\hline & $\begin{array}{c}\text { Cabo de } \\
\text { Santo } \\
\text { Agostinho }\end{array}$ & Local & Multicampus & Desvinculado & Segregação \\
\hline
\end{tabular}

Fonte: CALVO-SOTELO, 2011, adaptado pela autora.

Assim, verifica-se que a UNIBO adota o modelo de distribuição espacial do tipo Territorial, de estrutura Multicampus, enquanto o modelo de Localização referese ao Urbano, Difundido no tecido Urbano, e sua relação com a cidade do tipo Integração. Seus campi se inserem no espaço urbano, dentro dessa mesma filosofia de implantação.

A UFRPE, por sua vez, adota o modelo de distribuição espacial do tipo Local, de estrutura Multicampus, enquanto que o modelo de Localização refere-se ao Desvinculado, e sua relação com a cidade do tipo Segregação. Seus campi se inserem também com a mesma lógica de implantação.

Com esse entendimento, algumas reflexões são necessárias: (a) tanto a UFRPE quanto a UNIBO replicaram seus modelos e tipologias das unidades sedes para suas extensões; (b) a reprodução do modelo adotado pela UFRPE compromete a consolidação de suas extensões nos contextos em que se inserem, favorecendo a evasão escolar, pois conta com as dificuldades inerentes às características sociais e econômicas locais; (c) o processo de expansão de ambas as instituições ocorreram inicialmente sob a condição de extensão, tornando-se mais facilmente em unidade autônoma no caso da UNIBO, já que para a UFRPE apenas uma de suas extensões está em processo de emancipação, a UAG; (d) o planejamento estratégico é chave no processo de amadurecimento, qualificação e consolidação da instituição, além de responder mais rápido e de forma segura com o modelo Territorial, como se evidenciou no caso da UNIBO; (e) o modelo adotado pela UNIBO interage de forma mais rápida e forte com o desenvolvimento local e regional, dialogando com o tecido

Estudos Geográficos, Rio Claro, 17(1): 195-216, jan./jun. 2019 (ISSN 1678-698X) http://www.periodicos.rc.biblioteca.unesp.br/index.php/estgeo 
urbano e sua dinâmica a ponto de confundir-se um com o outro; (f) diferentemente ocorre com a UFRPE, cujo modelo adotado não dialoga com o tecido urbano e menos ainda com o dinamismo da cidade na qual se insere; (g) o modelo de localização Urbano responde concretamente ao dinamismo do espaço urbano, funcionando como diversificação de uso no espaço, diferentemente do modelo desvinculado cuja relação com a cidade fica bastante comprometida.

Ademais, sugere-se a renovação nos modelos e tipologias tratados por Calvo-Sotelo (2011) em razão da demanda atual oriunda do processo de internacionalização de IES. Considerando o caso da UNIBO, que apresenta uma unidade em Buenos Aires, Argentina, a sugestão é incorporar novo modelo, o Global, aos três outros indicados pelo autor, referindo-se àquelas instituições que já contam com extensões ou mesmo como unidades autônomas em outros países. Embora ambas as instituições tenham adotado como modelo de distribuição física multicampus, diferem em sua distribuição Territorial, denotando o sucesso do planejamento estratégico, com base no sistema Cidade-Universidade-Região, que considerou as potencialidades locais e regionais. Dessa forma, pode-se afirmar que é discrepante a aderência, a integração e a consolidação entre a UNIBO, a cidade e a região em que se insere em relação à situação da UFRPE e a cidade e região em que se situa. Isso se evidencia também em relação às unidades autônomas e às extensões respectivamente. Assim sendo, a proposta é a de se adotar um modelo territorial que seja coerente com as características urbanísticas locais, que se integre ao tecido urbano e, assim, contribua efetivamente para o desenvolvimento local e regional.

\section{REFERÊNCIAS}

ARAÚJO, Carla Busato Zandavalli Maluf de. Políticas Públicas de Permanência na Educação Superior Brasileira nos anos 2000. Artigo apresentado no XXII Seminário Nacional da Rede Universitas/Br: Políticas de Educação Superior no Brasil, realizado em Campo Grande/MS, promovido pelo GEPES - Grupo de Estudos e Pesquisas sobre a Educação Superior da ANPED - Associação Nacional de Pesquisa e Pós-graduação em Educação, 2014. Disponível em http://www.anped11.uerj.br/texto_Carla.pdf. Acesso 14/12/15.

CALVO-SOTELO, Pablo Campos. Arquitectura y Universidad en la sociedad contemporánea: innovación abierta y aprendizaje activo en las cuatro escalas espaciales. Artigo publicado na Revista CIAN - Revista de Historia de las Universidades, editada pelo Instituto Figuerola de Historia y Ciencias Sociales ISSN 1139-6628 / EISSN 1988- 8503 - v. 14, n. 2, 2011, pp. 149-182. Disponível em http://hosting01.uc3m.es/Erevistas/index.php/CIAN/article/view/1394/577. Acessado em 23/02/16.

DALLARI, Fiorella; CURIAZI, Roberta. Los espacios urbanos y los espacios culturales. Entre innovación y globalización. El cuadro Italiano e Brasileño. Revista Movimentos Sociais e Dinâmicas espaciais, Recife: UFPE/MSEU, v.01, n.02, $2012 . \quad$ Disponível em http://www.revista.ufpe.br/revistamseu/index.php/revista/article/view/29 Acessado em $21 / 11 / 2014$.

Estudos Geográficos, Rio Claro, 17(1): 195-216, jan./jun. 2019 (ISSN 1678-698X) http://www.periodicos.rc.biblioteca.unesp.br/index.php/estgeo 
IPEA - INTITUTO DE PESQUISAS ECONÔMICAS APLICADAS. Expansão para o interior - Governo inicia processo de descentralização do ensino superior. Revista Desafios do Desenvolvimento, ano 7, ed. 58, 2010. Disponível em http://www.ipea.gov.br/desafios/index.php?option=com_content\&view=article\&id=154 1 :catid=28\&ltemid=23. Acessado em 21/11/2014.

NEVES, R. R.; SILVEIRA, D. V. da; ALMEIDA, G. A. de; COSTA, K. M. S.. o paradigma da segregação dos campi universitários no Brasil: Distanciamento físico e implicações sociais. Artigo apresentado no III Seminário Internacional Urbicentros, realização do Programa de Pós-Graduação em Arquitetura e Urbanismo da Universidade Federal da Bahia, Salvador - Bahia, de 22 a 24 de outubro, 2012. Disponível em: http://www.ppgau.ufba.br/urbicentros/2012/ST258.pdf. Acesso em 27/01/16.

PINTO, Gelson de Almeida; BUFFA, Ester. Arquitetura, Urbanismo e Educação: Campi Universitários Brasileiros. Anais do VI Congresso Luso-Brasileiro de História da Educação, Uberlândia - Minas Gerais, de 17 a 20 de abril, 2006, pp. 5724-5746.

PRADO COELHO, Maria Lígia. Educación superior en Brasil Y los Estados Unidos: Privatización Y enseñanza de paga. Revista de la Educación Superior, No. $109, \quad$ Artigo $2, \quad 1999 . \quad$ Disponível em: http://www.anuies.mx/servicios/p_anuies/publicaciones/revsup/res109/art2.htm.Aces so em 10/10/14.

SANTOS, Boaventura de Souza; ALMEIDA FILHO, Naomar. A Universidade no Século XXI: para uma Universidade Nova. Coimbra: Edições Almedina, 2008.

UNIVERSIDADE FEDERAL RURAL DE PERNAMBUCO. Relatório de Atividades UFRPE/2013, 1‥ ed., Recife: EDURPE, 2014.

UNIVERSIDADE FEDERAL RURAL DE PERNAMBUCO. Relatório de Atividades UFRPE/2014, 1‥ ed., Recife: EDURPE, 2015.

UNIVERSIDADE FEDERAL RURAL DE PERNAMBUCO. Relatório de Atividades UFRPE/2015, 1‥ ed., no prelo.

UNIVERSITÀ DI BOLOGNA. Sitio da Universidade. Disponível em http://www.unibo.it/en/university/who-we-are/university-today/university-today. Acessado em 20/11/15.

VERGER, Jacques. A universidade na Idade Média. São Paulo: Ed. da Unesp, 1990.

Estudos Geográficos, Rio Claro, 17(1): 195-216, jan./jun. 2019 (ISSN 1678-698X) http://www.periodicos.rc.biblioteca.unesp.br/index.php/estgeo 